\title{
DOES ADMISSION HYPOTHERMIA PREDISPOSE TO INTRA-VENTRICULAR HEMORRHAGE IN VLBW INFANTS? A MULTI-CENTER STUDY
}

\author{
T. Smolkin ${ }^{1}$, S. Audeh ${ }^{2}$, Y. Bental ${ }^{3}$, Z. Haramati ${ }^{2}$, S. Blazer ${ }^{1}$, E. Litig ${ }^{3}$, R. Biton ${ }^{3}$, S. Dolberg ${ }^{2}$, I.R. Makhoul ${ }^{1}$ \\ ${ }^{I}$ Rambam Medical Center, Haifa, ${ }^{2}$ Ichilov Medical Center, Tel Aviv, ${ }^{3}$ Laniado Medical Center, Netanya, \\ Israel
}

Background and aim: The pathogenesis of IVH in VLBW is mainly associated with low GA and severity of respiratory disease. The role of admission hypothermia (AHT) in causing IVH has not yet been fully verified. We searched risk factors for IVH in VLBW infants while focusing on AHT.

Methods: We included 300 VLBW infants from 3 NICUs. Variables known to be associated with development of IVH were collected. AHT was defined as admission temperature $\leq 35.5^{\circ} \mathrm{C}$ as measured by rectal thermometer. Head US was performed at 2-5 and 6-10 days of age and before discharge.

Results: Multivariate logistic regression showed that 5 variables were significantly associated independently with IVH: GA ( $\mathrm{p}=0.0003$; OR=0.6; 95\% C.I. : 0.46-0.79); head circumference $(\mathrm{p}=0.016 ; 1.43,1.07-1.91)$; nitric oxide $(\mathrm{p}=0.001 ; 7.9,2.26-27.65) ; \mathrm{PCO} 2<30 \mathrm{mmHg}(\mathrm{p}=0.001 ; 3.54,1.69-7.43)$; base deficit $>10$ $(\mathrm{p}=0.007 ; 3.22,1.38-7.52)$. Four variables were significantly associated independently with severe IVH grades 3-4: GA $(\mathrm{p}=0.003 ; 0.68,0.53-0.87)$; hypotension $(\mathrm{p}=0.013 ; 6.1,1.46-25.4)$; base deficit $>10$ $(\mathrm{p}=0.0001 ; 7.65,2.47-23.7) ;$ hyponatremia $<130 \mathrm{mEq} / \mathrm{L}(\mathrm{p}=0.007 ; 5.68,1.61-20)$. AHT at $\leq 35.5^{\circ} \mathrm{C}$ was not significantly associated with IVH in the regression model.

Conclusions: AHT $\leq 35.5^{\circ} \mathrm{C}$ and $\leq 35.0^{\circ} \mathrm{C}$ were not significantly associated with development of IVH. Nonetheless, GA, head circumference, nitric oxide, hypocarbia and base deficit $>10$ were strongly associated with IVH. Whether AHT confers brain protection in VLBW infants is yet to be determined. 